\title{
Analysis of corneal esthesia in patients undergoing photorefractive keratectomy
}

\author{
Análise da estesia corneal em pacientes submetidos à ceratectomia fotorrefrativa
}

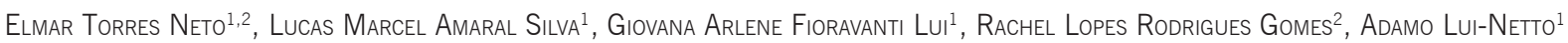

\begin{abstract}
Purpose: To quantitatively analyze corneal esthesia in patients undergoing photorefractive keratectomy (PRK) surgery.

Methods: Forty-five patients selected for PRK in one eye underwent corneal esthesia using a Cochet-Bonnet esthesiometer preoperatively and 30 and 90 days postoperatively. Patients with a refractive diopter error of 4 or greater received intraoperative $0.02 \%$ mitomycin C for $20 \mathrm{~s}$.

Results: Twenty-four (53.3\%) of the 45 eyes received intraoperative $0.02 \% \mathrm{mi}$ tomycin. Decreased sensitivity was observed on postoperative day 30 . By postoperative day 90 , corneal esthesia had normalized but remained $14.9 \%$ lower than preoperative levels. In the mitomycin group, no recovery of corneal esthesia to normal sensitivity levels was observed. The mean esthesiometer level was $39.2 \mathrm{~mm}$ on postoperative day $90(P<0.001)$.

Conclusions: The results of the present study demonstrate recovery of corneal esthesia to normal levels at 90 days postoperatively in patients who did not receive mitomycin C. In patients administered mitomycin C, a $23.59 \%$ reduction in the corneal touch threshold was observed compared with preoperative levels indicating a failure of recovery to normal levels.
\end{abstract}

Keywords: Mitomycin; Cornea; Photorefractive keratectomy; Myopia; Prospective studies

\section{RESUMO}

Objetivo: Análise quantitativa da estesia corneal em pacientes submetidos à cirurgia refrativa $(P R K)$.

Métodos: Estudo prospectivo, longitudinal e intervencionista, analisando 45 olhos com estesiômetro de Cochet Bonnet no período pré-operatório, no $30^{\circ}$ dia após a cirurgia e no $90^{\circ}$ dia após cirurgia refrativa. Os pacientes com erro refracional maior ou igual a 4 dioptrias, foram submetidos ao uso de mitomicina 0,02\%, por período de 20 segundos no intraoperatório.

Resultados: Observou-se diminuição da sensibilidade corneal no $30^{\circ}$ dia em todos os olhos, retornando a níveis próximo ao normal no 90 dia, apresentando redução média final de 14,9\%. Mitomicina C foi utilizada em 24 (53,3\%) dos 45 olhos examinados. No grupo que recebeu mitomicina $C$, não houve recuperação da estesia normal (média de 39,2 mm) ( $p<0,001)$, após 90 dias de cirurgia.

Conclusão: Combasenos resultados obtidos, verificamos que ocorreu recuperação da estesia corneal próximo ao normal 90 dias após a cirurgia, porém inferior aos valores iniciais, no grupo sem o uso de mitomicina C intraoperatória. No entanto, no grupo submetido ao uso de mitomicina, não houve a recuperação da sensibilidade corneal a níveis normais, mesmo após o período de 90 dias.

Descritores: Mitomicina; Córnea; Ceratectomia fotorrefrativa; Miopia; Estudos prospectivos

\section{INTRODUCTION}

Refractive surgery with excimer lasers is used worldwide for the treatment of myopia, hyperopia, astigmatism, corneal scar, and other diseases ${ }^{(1-3)}$. Postoperative corneal hypoesthesia has been reported as a consequence of refractive surgery. The photorefractive keratectomy (PRK) technique, despite being considered a safe procedure, has been reported as associated with marked reduction in corneal sensitivity ${ }^{(4-8)}$.

The cornea is one of the regions of the human body that has the highest amount of naked nerve endings and, therefore, has a high level of pain sensitivity. The sensory innervation of the cornea is essential in maintaining corneal integrity ${ }^{(9,10)}$. The touch sensitivity threshold of the cornea, particularly in the center, is rather low. Loss or reduction of normal corneal sensitivity may compromise reactions to flash, delay epithelial healing, reduce tear flow, and predispose to the development of neurotrophic keratitis, sterile corneal necrosis, and infectious keratitis ${ }^{(11,12)}$.
The PRK procedure consists of removing the corneal epithelial layer with its basement membrane followed by excimer laser photodisruption of Bowman's layer and the anterior portion of the corneal stroma resulting in impairment of nerve endings in the nerve plexus of the subepithelial and anterior stromal|(13,14).

The Cochet-Bonnet esthesiometer is an established tool for determining corneal sensitivity by evaluating the corneal touch threshold (CTT). This instrument contains an adjustable nylon filament with a defined diameter, which is applied in different lengths to the cornea in five prescribed regions. The length of the nylon filament estimates the applied pressure on the corneal surface. The shorter the filament, the more pressure is applied to the cornea and vice versa. The CTT is reached as soon as a blink reflex is consistently elicited with the same pressure or length of filament. Estimation of corneal sensitivity may be necessary for the diagnosis and monitoring of eye diseases or the evaluation of corneal healing following surgery ${ }^{(15)}$.
Funding: No specific financial support was available for this study.

Disclosure of potential conflicts of interest: None of the authors have any potential conflicts of interest to disclose.

Corresponding author: Elmar Torres Neto. Universidade Federal de São Paulo. Departamento de Oftalmologia, Secretaria Administrativa. Rua Botucatu, 821, 1a andar, São Paulo, SP - 04023-062 Brazil - E-mail: elmaroft@hotmail.com

Approved by the following research ethics committee: Irmandade da Santa Casa de Misericórdia de São Paulo; protocolo 261728. 
The present study aimed to evaluate preoperative and postoperative corneal sensitivity following PRK surgery with and without intraoperative use of mitomycin $\mathrm{C}$.

\section{METHODS}

We performed a prospective, longitudinal, interventional study. Patients were enrolled between December 2013 and January 2014, with all surgeries performed on April 3, 2014. Patients were advised to discontinue the use of contact lenses 2 weeks prior to surgery.

Individuals over 21 with stable ametropia (considered stable when no variation $>0.25 \mathrm{D}$ in static refraction is observed within 1 year), a spherical equivalent between -1.50 and $-8.00 \mathrm{D}$, and a cylindrical component of $<2.00 \mathrm{D}$ with normal corneal topography were enrolled in the present study. Patients unavailable for control visits or with previous eye surgery, corneal thickness $<500 \mu \mathrm{m}$, systemic diseases (i.e., collagenosis, uncontrolled diabetes, and immunodeficiency), or eye diseases that could affect surgical outcomes were excluded from the present study.

All tests were performed 1 week prior to surgery (Pre), on postoperative day 30 (30 post), and postoperative day 90 (90 post). Corneal sensitivity was measured in the central region using a Cochet-Bonnet esthesiometer ${ }^{(9)}$. The esthesiometer filament was applied perpendicularly to the pressing surface of the cornea obtained by bending a small portion (approximately 5\%) of its length. The procedure was repeated with a gradual reduction in the length of wire in 5-mm increments. Patients reported perception of the test at every touch of the filament. To confirm patient responses, the central area of the cornea was tested three times with a minimum interval of $60 \mathrm{~s}$. The greatest length of the wire that elicited a response to the stimulus was recorded in millimeters and considered the CTT of the corneal central area ${ }^{(15)}$. Normal values for corneal sensitivity evaluated by Cochet-Bonnet esthesiometry are $>40 \mathrm{~mm}$ in the central region of the cornea. All tests were conducted in the same environment in a closed room.

Pattern delineation and mechanical scarification (spatula) of the cornea was performed followed by photoablation using an EC5000 ${ }^{\circledR}$ excimer laser (Nidek Inc. Fremont, California) targeting a 6.5-mm ablation zone. Patients with a greater refractive error of $4 \mathrm{D}$ were intraoperatively administered $0.02 \%$ mitomycin C for 20 s with subsequent washing with balanced saline solution. A bandage contact lens was maintained for 7 days in all patients. Standard prescription eye drops included tobramycin $0.3 \%$ and dexamethasone $0.1 \%$ (Tobradex ${ }^{\circledR}$, Alcon Laboratories, Inc. Fort Worth, TX) instilled as one drop every $4 \mathrm{~h}$ for 7 days and ketorolac tromethamine eye drops (Acular ${ }^{\circledR}$, Alcon Laboratories, Inc. Fort Worth, TX) instilled every $6 \mathrm{~h}$ for 40 days.

Statistical analyses were initially performed in a descriptive manner by calculating a number of summary measures including mean, median, minimum and maximum values, standard deviation, absolute and relative frequencies (percentage), and individual graphic profiles (lines). The inferential analyses performed to confirm or refute findings of descriptive analyses were: analysis of variance in blocks with two random factors (patient and side effect) compared with central corneal sensitivity $(\mathrm{mm})$ at varying study time points (preoperatively, and 30 and 90 days postoperatively) adjusted for mitomycin use and gender. Comparisons were performed using the Tukey method (Neter et al., 1996) when necessary ${ }^{(16)}$. A significance level $a=5 \%$ was set for all inferential analyses. Data were entered into Excel 2010 spreadsheets for Windows for proper storage of information. Statistical analyses were performed using the statistical program, R, version 2.15.2.

\section{RESULTS}

The selected sample in the present study consisted of 45 patients comprising 23 (52.2\%) women and 22 (47.8\%) men. The mean age was $31.8 \pm 7.4$ years, ranging from 21 to 46 years. Mitomycin C was administered to 24 eyes (53.3\%).

The following CTT values for the sensitivity in the central region of the cornea were obtained: $51.1 \pm 7.4$ in the preoperative period; $26.7 \pm 9.3$ at 30 days postoperatively; and $43.2 \pm 8.3$ at 90 days postoperatively. A statistically significant difference in CTT values was observed between the three study time points $(P<0.001$; Table 1 ; Figure 1). The inferential results confirmed the results of descriptive analyses, with no significant differences in quantitatively measured sensitivity observed between the three study time points (Table 2). Sensitivity values in the central region $>40 \mathrm{~mm}$ were considered normal, with 25 (55.6\%) of 45 eyes found to have normal sensitivity on postoperative day 90 .

Decreased sensitivity in the central region between the preoperative values and postoperative day 30 was also evaluated. The reduction was estimated using the following expression:

$$
\text { reduction }=\frac{(\text { pre }-30 \text { days })}{\text { pre }} \cdot 100 \%
$$

The average reduction in central region sensitivity observed in the 45 eyes was $45.9 \%$, ranging from $33.3 \%$ to $75.0 \%$ with a standard deviation of $23.2 \%$. The corneal esthesia analysis performed preoperatively and on postoperative day 90 revealed an average reduction of $14.9 \%$, ranging from $6.7 \%$ to $41.7 \%$ with a standard deviation of $13.6 \%$.

Mean sensitivity values in the group administered mitomycin C preoperatively and on postoperative day 90 groups were $51.3 \pm 6.1$ and $39.2 \pm 6.7$, respectively $(P<0.001)$. In patients who did not receive intraoperative mitomycin, mean sensitivity values preoperatively and on postoperative day 90 were $51.0 \pm 8.7$ and $47.9 \pm 7.7$, respectively $(P=0.021$; Table 3$)$.

\section{DISCUSSION}

In the present study, we observed a reduction in corneal sensitivity on postoperative day 30 and a recovery of sensitivity to normal values on postoperative day 90; however, corneal sensitivity did not

Table 1. Summary of central corneal sensitivity measurements ( $\mathrm{mm}$ ) over time

\begin{tabular}{lccccccc}
\hline & \multicolumn{7}{c}{ Central corneal sensitivity $(\mathbf{m m})$} \\
\cline { 2 - 8 } & $\boldsymbol{N}$ & Mean & Median & Minimum & Maximum & Standard deviation & $\boldsymbol{P}$-value \\
\hline Preoperative & 45 & 51.1 & 50.0 & 30.0 & 60.0 & 7.4 & $<.001^{\text {a }}$ \\
30 days & 45 & 26.7 & 25.0 & 15.0 & 50.0 & 9.3 \\
90 days & 45 & 43.2 & 45.0 & 30.0 & 60.0 & 8.3 & \\
\hline
\end{tabular}

${ }^{a}=$ analysis of variance in blocks with two random factors. 
fully recover to preoperative values $(P<0.001)$. These data are consistent with previous literature demonstrating reduced central corneal sensitivity in the first month following PRK. Studies conducted in rabbits, which have a similar inervacional structure to the human cornea, have demonstrated the reappearance of peripheral neurites around the sixth week following PRK ${ }^{(17)}$. Likewise, Pallikaris et al. observed recovery of central corneal sensitivity to values considered normal or near normal in the third month after PRK ${ }^{(18)}$.

In the mitomycin $C$ group of the present study, no recovery of corneal esthesia to normal values was observed ay 90 days after the procedure, with a mean value of $39.2(P<0.001)$. As mitomycin was only used in patients with ablation $>4 \mathrm{D}$, the lack of sensitivity recovery

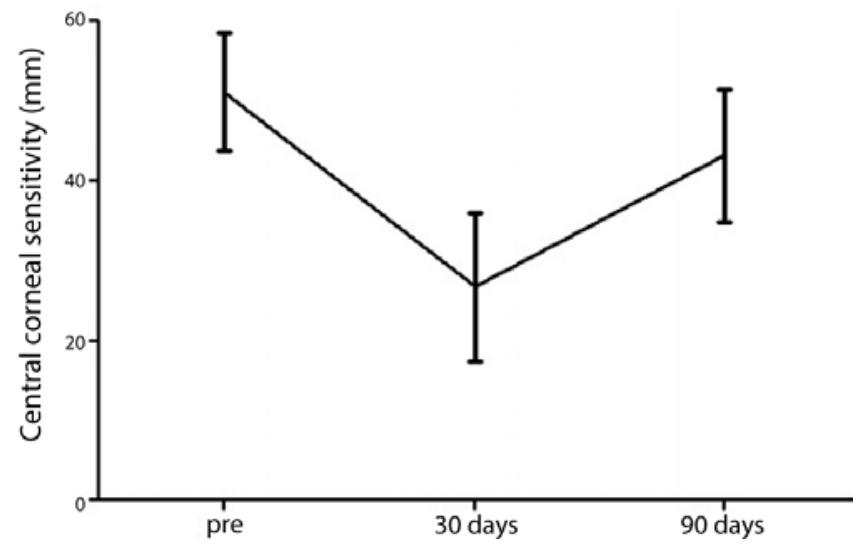

Figure 1. Mean measures of sensitivity in the central region of the cornea $(\mathrm{mm})$ from the eyes of patients with standard deviations according to study time point.

Table 2. Results of multiple comparisons by the Tukey method of quantitative evaluations of central cornea region sensitivity $(\mathrm{mm})$ over time

\begin{tabular}{lc}
\hline Comparison & P-value \\
\hline Preoperative vs. 30 days postoperatively & $<0.001$ \\
Preoperative vs. 90 days postoperatively & $<0.001$ \\
30 days postoperatively vs. 90 days postoperatively & $<0.001$ \\
\hline
\end{tabular}

during the expected period may be attributable to the greater amount of tissue removed in these patients. However, the relationship between ablation depth and decreased corneal sensitivity following photorefractive surgery remains unclear ${ }^{(19)}$. Although Chuck et al. reported that the measurement of the decreased corneal sensitivity induced by laser-assisted in situ keratomileusis (LASIK) appears to be independent of the depth of the ablation, other studies have shown that the depth of cut or ablation in PRK affects recovery of corneal sensitivity ${ }^{(20)}$. Campos et al. reported patients with a preoperative myopia of -6.50 D recovered $95.7 \%$ of central corneal sensitivity after 3 months in a series of 14 eyes that underwent PRK, while patients with severe myopia (>-9.00 D) recovered $86.2 \%$ of the original cornea sensitivity to values within normal limits ${ }^{(21)}$.

Péres-Santoja et al. and Matsui et al. investigated the sensitivity of the central cornea in similar patients groups but without the administration of $0.02 \%$ mitomycin C and observed a recovery of esthesia 90 days after the procedure to preoperative values ${ }^{(14,19)}$. Thus, although patients administered mitomycin C in the present study had greater amounts of tissue removed (between -4.00 and $-8.00 \mathrm{D}$ ), this amount was relatively small compared with previous comparable studies, and corneal sensitivity would still be expected to return to normal levels in these patients.

Farahi et al. compared CTT values between PRK alone and PRK with mitomycin C over a 12-month period postoperatively. The authors observed a reduction in CTT values in both groups postoperatively, with no statistically significant difference observed between $\operatorname{groups}^{(22)}$.

Corneal sensitivity can be influenced by many variables including age, iris color, hormonal changes, type of eyelid closure, and psychological state. The determination of any single factor responsible for reduced sensitivity corneal in individual patients is questionable, particularly in patients undergoing refractive surgery ${ }^{(9)}$.

Further studies are required to evaluate late recovery of corneal sensitivity in patients administered mitomycin $C$ and compare outcomes with patients undergoing other refractive procedures. Recovery following LASIK typically occurs at approximately 6 months postoperatively ${ }^{(14,23)}$.

\section{CONCLUSION}

The results of the present study demonstrate corneal sensitivity following PRK recovered to normal levels at 90 days after surgery in patients who did not receive mitomycin C; however, a 6.08\% reduction in corneal sensitivity was observed at this time point compared with preoperative levels.

In patients administered mitomycin C, a $23.59 \%$ reduction in CTT compared with preoperative levels was observed who did not recover to normal levels by postoperative day 90 .

Table 3. Summary of pre and $90^{\text {th }}$ postoperative central cornea sensitivity $(\mathrm{mm})$ measurements according mitomycin use

\begin{tabular}{|c|c|c|c|c|c|c|c|c|}
\hline & & \multicolumn{6}{|c|}{ Central sensitivity (mm) } & \multirow[b]{2}{*}{$P$-value } \\
\hline & & $N$ & Mean & Median & Minimum & Maximum & Standard deviation & \\
\hline Mitomycin & Preoperative & 24 & 51.3 & 50.0 & 40.0 & 60.0 & 6.1 & $<0.001^{\mathrm{a}}$ \\
\hline \multirow[t]{2}{*}{ Without mitomycin } & Preoperative & 21 & 51.0 & 50.0 & 30.0 & 60.0 & 8.7 & $0.021^{\mathrm{a}}$ \\
\hline & 90 days post & 21 & 47.9 & 45.0 & 30.0 & 60.0 & 7.7 & \\
\hline
\end{tabular}

$\mathrm{a}=$ analysis of variance in blocks with two random factors. 


\section{REFERENCES}

1. Hersh PS, Stulting RD, Steinert RF, Waring GO, $3^{\text {rd }}$, Thompson KP, O'Connell M, et al. Results of phase III excimer laser photorefractive keratectomy for myopia. The Summit PRK Study Group. Ophthalmology. 1997;104(10):1535-53.

2. Campos M, Hertzog L, Garbus J, Lee M, McDonnell PJ. Photorefractive keratectomy for severe postkeratoplasty astigmatism. Am J Ophthalmol. 1992;114(4):429-36.

3. Vestergaard AH, Hjortdal JO, Ivarsen A, Work K, Grauslund J, Sjolie AK. Long-term outcomes of photorefractive keratectomy for low to high myopia: 13 to 19 years of follow-up. J Refract Surg. 2013;29(5):312-9.

4. Biermann H, Grabner G, Baumgartner I, Reim M. [Corneal sensibility following epikeratophakia]. Klin Monbl Augenheilkd. 1992;201(1):18-21. German.

5. Koenig SB, Berkowitz RA, Beuerman RW, McDonald MB. Corneal sensitivity after epikeratophakia. Ophthalmology. 1983:90(10):1213-8.

6. Kohlhaas M, Bohm A, Schmitz N, Draeger J. [Measuring corneal sensitivity with the air aesthesiometer in comparison with the Draeger electromagnetic air aesthesiometer]. Ophthalmologe. 1994;91(5):685-90. German.

7. Linna TU, Vesaluoma MH, Perez-Santonja JJ, Petroll WM, Alio JL, Tervo TM. Effect of myopic LASIK on corneal sensitivity and morphology of subbasal nerves. Invest Ophthalmol Vis Sci. 2000:41(2):393-7.

8. Murakami Y, Manche EE. Prospective, randomized comparison of self-reported postoperative dry eye and visual fluctuation in LASIK and photorefractive keratectomy. Ophthalmology. 2012;119(11):2220-4.

9. Martin XY, Safran AB. Corneal hypoesthesia. Surv Ophthalmol. 1988;33(1):28-40.

10. Schimmelpfennig B. Nerve structures in human central corneal epithelium. Graefe's archive for clinical and experimental ophthalmology = Albrecht von Graefes Arch Clin Exp Ophthalmol. 1982;218(1):14-20,

11. Beuerman RW, Schimmelpfennig B. Sensory denervation of the rabbit cornea affects epithelial properties. Experimental neurology. 1980;69(1):196-201.

12. Credie MG, Nishiwaki-Dantas MC, Felberg S, Amorim F, Dantas PE. [Quantitative chan- ges in tear film after refractive surgery: comparative study between PRK and LASIK]. Arq Bras Oftalmol. 2007;70(1):23-30. Portuguese.

13. Kanellopoulos AJ, Pallikaris IG, Donnenfeld ED, Detorakis S, Koufala K, Perry HD. Comparison of corneal sensation following photorefractive keratectomy and laser in situ keratomileusis. J Cataract Refract Surg. 1997;23(1):34-8

14. Perez-Santonja JJ, Sakla HF, Cardona C, Chipont E, Alio JL. Corneal sensitivity after photorefractive keratectomy and laser in situ keratomileusis for low myopia. Am J Ophthalmol. 1999;127(5):497-504.

15. Chao C, Stapleton F, Badarudin E, Golebiowski B. Ocular surface sensitivity repeatability with Cochet-Bonnet esthesiometer. Optom Vis Sci. 2015;92(2):183-9.

16. Neter J, Wasserman W. Applied linear statistical models. $4^{\text {th }}$ ed. Chicago: Irwin; 1996.720 p

17. Trabucchi G, Brancato R, Verdi M, Carones F, Sala C. Corneal nerve damage and regeneration after excimer laser photokeratectomy in rabbit eyes. Invest ophthalmology Vis Sci. 1994;35(1):229-35.

18. Pallikaris IG, Papatzanaki ME, Stathi EZ, Frenschock O, Georgiadis A. Laser in situ keratomileusis. Lasers Surg Med. 1990;10(5):463-8.

19. Matsui H, Kumano Y, Zushi I, Yamada T, Matsui T, Nishida T. Corneal sensation after correction of myopia by photorefractive keratectomy and laser in situ keratomileusis. J Cataract Refract Surg. 2001;27(3):370-3.

20. Chuck RS, Quiros PA, Perez AC, McDonnell PJ. Corneal sensation after laser in situ keratomileusis. J Cataract Refract Surg. 2000;26(3):337-9.

21. Campos M, Hertzog L, Garbus JJ, McDonnell PJ. Corneal sensitivity after photorefractive keratectomy. Am J Ophthalmol. 1992;114(1):51-4.

22. Farahi $\mathrm{A}$, Hashemi $\mathrm{H}$, Mehravaran S. The effects of mitomycin $\mathrm{C}$ on tear function after photorefractive keratectomy: a contralateral comparative study. J Refract Surg. 2013; 29(4):260-4.

23. Huang JC, Sun CC, Chang CK, Ma DH, Lin YF. Effect of hinge position on corneal sensation and dry eye parameters after femtosecond laser-assisted LASIK. J Refract Surg. 2012;28(9):625-31. 